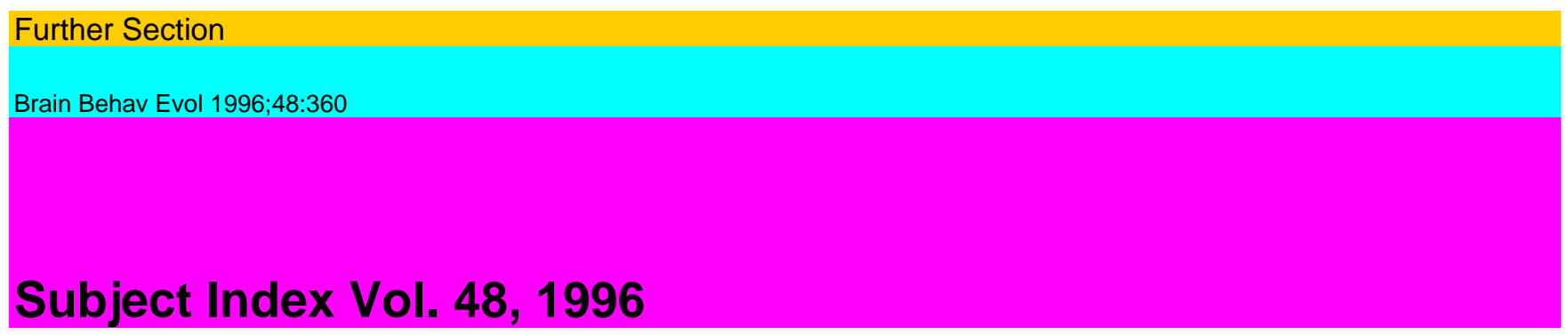

Agnathans 248 Agonistic interactions 213 AUometry 16 Ammocoete 297 Amphibian 70 Anterograde tracing 205 Audition 103,137 Auditory pathway 103 Avomic behavior 165

Bats 130

Bicolor damselfish 213 17/18a Border 221 Brain 213

- evolution 237

- structure 16 Brainstem 103

Carassius auratus 115

Catecholamines 70

Cell morphology 338

Central pattern generator 287

Centrifugal visual system 277

Chewing burst 94

Cholera toxin 307

Cichlids 137

Commissural subcortical pathway 1

Craniates 248

Distribution 27 Dopamine 70, 94 Dorsal light reflex 115

- terminal nucleus 1 Dorsomedial hypothalamus 70

Electroreception 27 Electroreceptor 27 Embryos 16 Epinephrine 70 Escape 137 Evolution 103,121,262

Feeding 157,297 Fiber connections 338 Fluorescent tracer 205 FluoSpheres 221 Functional unit 55

GABA 277 Golden hamster 221 Goldfish 137,205 Growth 16 Guinea pig 94 Gustation 262

Hagfish(es) 237,248,262 Haloperidol 94 5-HIAA 213 Homeobox genes 237 Horizontal optokinetic reflex 1 Horseradish peroxidase 277

Immunogold 277 Indoleamines 70 Inferior olive 1 Innervation pattern 55 Isthmooptic nucleus 277

Killdeer 16 Kmemajics 157

Lamprey(s) 237,248,262,277,287,297 Lateral geniculate nucleus 121

- line 55

- $\quad$ - systems 262 Lepidoptera 130 Locomotion 287

Mantis(es) 173, 191 Mantodea 191 Marsupial 103,157 Mastication 94 Mauthnercell 137 Mechanoreceptor 27 Mechanosensory lateral line 137 Metamorphosis 55 Monoamines 70 Motion analysis 173,191

NADPH diaphorase 221 Neural circuits 287 Neuroethology 130 Neuronal connections 205 Norepinephrine 70 NOS neurons 221 ftucieus, optic tract 1

Octavolateralis 137 Oculomotor 1 Olfaction 262 Ontogeny 157,248 Opossum 1,157 Oral movements 94 Origin of vertebrates 237

Paraventricular organ 70 Platypus 27

Praying mantis 173, 191 Predation 137

Predatory behavior 173

- strike 191

Prey capture 173,191

- localization 173,191Primates 121

Rattlesnake predatory behavior 165 Reorganization 55 Respiration 297 Retinal ganglion cells 277

- projections 121, 307Retrograde tracing 205Rhythmic behaviour 130Rhythmogenesis 287 
Sensorimotor integration 137 Sensory processing 130 Serotonin 70,213 Shorebirds 16 Snipe 16 Specialization 103 Sphodromantis lineola 173,191 Spinal cord 287

- $\quad$ interneurons 287Stress 213Subdivision 338Suckling 157Swimming 287

Tarsius bancanus 121 Telencephalo-habenulo-interpeduncular

system 205 Telencephalon 338 Teleost 338 Thalamus 121 Tiger moths 130 Time 94

Torus longitudinalis 115 Turtles 307

\section{Ultrastructure 27}

Velum 297 , Vestibular systems 262 Vision 137,262 Visual behavior 115

- callosal neurons 221

- cortex 221 Visual pathway(s) 307

- $\quad$ - evolution 307 Vomeronasal organ 165

X. Xenopus laevis 55 